\title{
1Changing cultures, changing environments: a novel means of investigating the effects of introducing 2non-native species into past ecosystems
}

\author{
3Jacqueline Pitta ${ }^{\mathrm{a}}$, Phillipa K. Gillingham ${ }^{\mathrm{a}}$, Mark Maltby ${ }^{\mathrm{b}}$, Richard Stafford ${ }^{\mathrm{a}}$ and John R. Stewart ${ }^{\mathrm{a}}$ \\ $4^{\mathrm{a}}$ Department of Life and Environmental Sciences, Bournemouth University, Talbot Campus, Poole \\ $5^{b}$ Department of Archaeology, Anthropology and Forensic Science, Bournemouth University, Talbot Campus, Poole \\ 6
}

7Keywords: Chicken; Domestication; Bayesian belief networks; Biotic interactions

8

9Abstract: Descended from junglefowl of Asia and South-east Asia, the chicken was introduced into Europe 10during the first millennium BCE. As one of the most recently domesticated species, it makes an excellent case 11study for investigating the consequences of such introductions to past ecological communities. We present a 12unique application of a novel ecological method to explore multiple past interspecies relationships. Analysing the 13faunal record using a Bayesian belief network, which allows for the analysis of multiple interspecies relationships 14simultaneously, indicates that the chicken has more affinity with other domestic birds rather than domestic 15 mammals in terms of species interactions. We find that the introduction of the chicken affected fox, partridge, 16pigeon and rat, but the success of the chicken was most affected by responses to abiotic variables, rather than 17biotic interactions. As the method is not limited to environmental variables, we also examined the effect of 18recovery method and demonstrate that sieving would enhance the frequency of small animal remains recovered 19 from archaeological sites.

211. Introduction: Relationships between different species, otherwise termed inter-specific interactions, can be 22both positive and negative. Interactions usually take the form of competition, predation, herbivory, and symbiosis 23(Lang and Benbow 2013). Symbiosis, literally meaning 'living-together', encompasses commensalism, 24amensalism, parasitism and mutualism, whereby only the latter is a mutually beneficial relationship and is not 25necessarily equally so (Parmentier and Michel 2013). Within ecological communities these relationships become 26 established over time but can be disrupted by environmental change or by the introduction of non-native species. 27Introducing non-native species into a new environment can cause dramatic changes in both the invader and the 28native populations within a very short period (as little as fifty years (approximately 100 chicken generations)) 29(Mooney and Cleland 2001). Niche displacement, hybridisation and reorganisation of mutual relationships can all 30 be consequences of such an introduction. Investigation of past ecological communities has identified unusual 31compositions of species assemblages compared to what might be expected today, which may cause 32evolutionary change (Stewart 2009).

33

34As a bird that has descended from junglefowl of Asia and Southeast Asia, and then been transported to Europe 35by people, the chicken successfully acclimated to different environments (Pitt et al. 2016). The subsequent effect $360 f$ this has not been studied, making the chicken an interesting case study for evaluating the impact of 
37introducing non-native species into new environments. Analysing changes in interactions between species found 38together in the faunal record over time enables us to examine the effect of the introduction of the chicken on its 39ecosystem. Investigating responses to various factors can help determine whether changes in communities 40occurred because of human intervention or natural change. Examination of species interactions is not new to 41archaeology, but investigation usually focuses primarily on human use of animals as a product, rather than how 42 species affect one another. It is usually limited to the primary domestic species, and often only mammals.

43

44Yet the presence of humans and the animals they keep has an effect beyond the domestic sphere, directly and 45indirectly. O'Connor (1993) discussed the displacement of certain groups of birds by facultative carnivores and 46carrion-feeders, particularly those which rely on other live species for food or have specific dietary needs. The 47consequence is that certain species should be expected to be encountered in faunal remains, and where this 48pattern is not found, then other factors must be responsible. Synanthropic species benefit from association with 49humans but usually have habitats outside of human settlements. Synurbanisation is defined as the 'highest level 50of synanthropisation' (Boev 1993, 145) and includes species which nest in human settlements. Human 51perception of synanthropic, and particularly commensal species, varies greatly. Commensal species are drawn 52to human habitations for food and shelter, and might be enjoyed, reviled, tolerated or hunted (O'Connor 2013a).

54Understanding complex networks of species interactions related to other species or to changing environments is 55 challenging. One of the oft-noted issues in ecological studies is the lack of incorporation of biotic relationships as 56opposed to models based purely on abiotic variables (Pearson and Dawson 2003; Baselga and Araújo 2009; 57Soberón and Nakamura 2009; Wisz et al. 2013). Ecological 'community models' attempt to incorporate multiple 58biotic species interactions to address fine scale variability (Mclnerny and Purves 2011; Kissling et al. 2012; 59Araújo and Rozenfeld 2014; Pollock et al. 2014). Such models could be beneficial to archaeological 60interpretation. Rather than using them to predict where species might occur, as with ecological applications, it is 61the interaction itself which is of most interest to archaeology.

62

63Bayesian Belief Network models (Stafford et al. 2015; Spiers et al. 2016) offer an effective means of 64understanding complex networks of species interactions. The model predicts how changes in certain variables, $65 f o r$ example an increase in frequency of chicken, would affect other species, for example, other edible birds, 66other fighting birds, predators and commensal species. The method is not limited to environmental factors, and 67 can also be used to investigate more practical aspects of archaeology, such as how archaeological recovery 68 methods affect the retrieval of small animal bones. It is generally assumed that sieving will result in greater 69recovery of small animal bones (Wilkinson 2007, 87; Davis 2012, 29); however, there are instances where 70sieving has produced limited or no additional results (Zeiler and de Vries 2008; Elevelt 2012). Given additional 71costs (time and financial) associated with this process it is important to understand how useful it might be. We 72present a methodology for adapting archaeological data for use in a BBN, and use the technique to assess 
73whether introducing the chicken into a new ecosystem had an impact on other species, whether other species or 74abiotic variables influenced the success of the introduction of chicken, and whether the method can be used to 75 identify recovery biases.

\section{6}

772. Materials and Methods: We performed four different models using specific variables. The first two models 78 use only biotic (species) variables, the second considers biotic and abiotic variables, including climate, location, 79and site type, and the final model addresses recovery method on species frequency.

80

81Matrices of faunal assemblages, including species found together, date, site-type, number of identified 82specimens (NISP), recovery and bone condition were extracted from a pan-European database of assemblages 83containing bird bones (Pitt 2017; Pitt and Stewart in press). The dataset includes sites from ca. 3000 BCE to 500 84CE (Figure 1). For clarity of interpretation, assemblages from site phases dating from ca. $3000-800 \mathrm{BCE}$ are 85referred to as 'period 1'; '800 BCE - 0/42 CE' as 'period 2'; and '1 - 500 CE' as 'period 3'. The dates broadly 86correspond with the Bronze Age, Iron Age and Roman periods in Europe, but it is recognised that the Bronze 87Age ended at different times in different parts of Europe, that the Greek civilisation and Roman Republic fall 88within the time frame of 'period 2', and not all phases in Europe in 'period 3' were occupied by the Romans. 89Period 2 includes sites from the United Kingdom up until $42 \mathrm{CE}$, due to the later arrival of the Romans in this 90region.

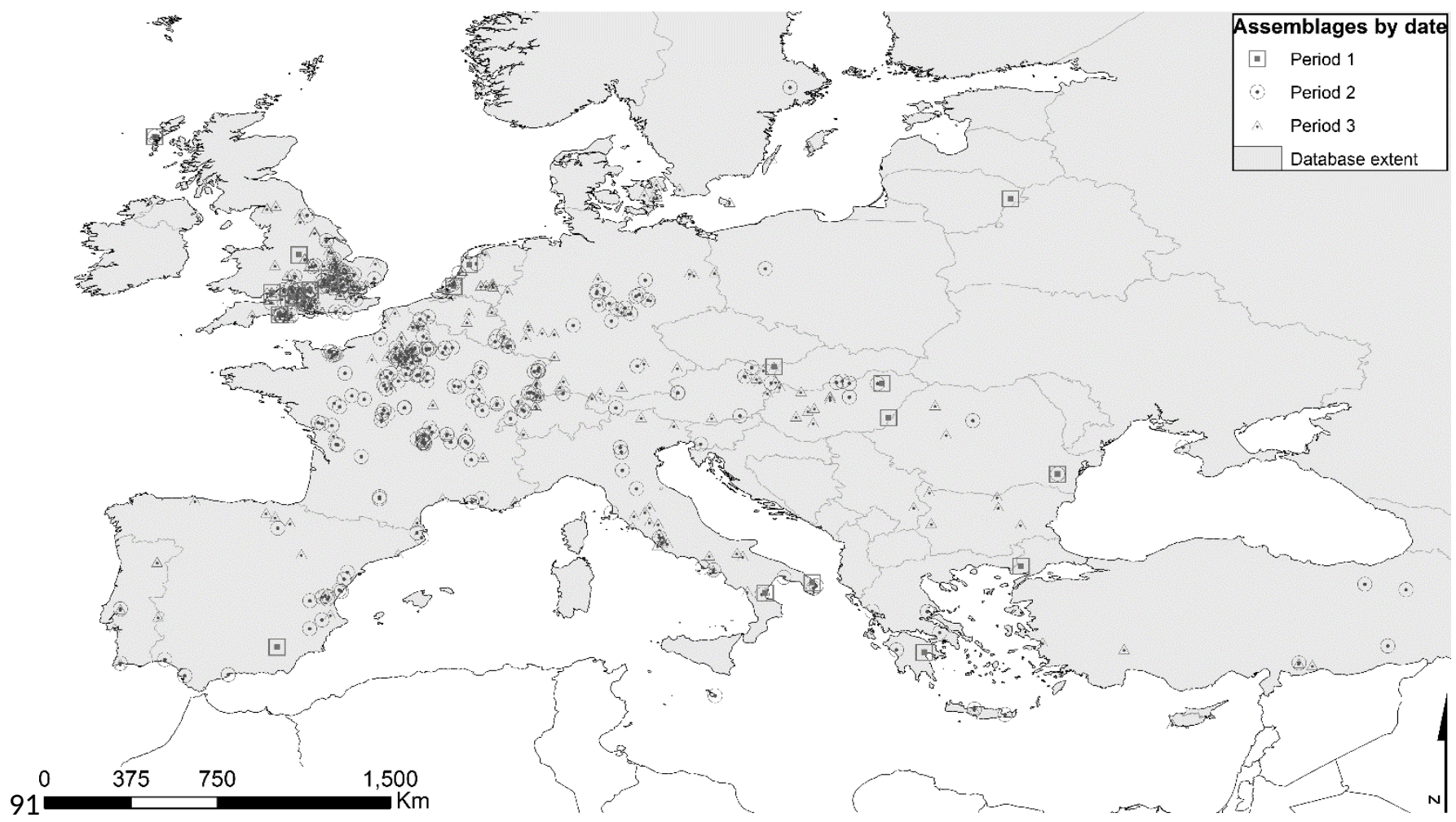

92Figure 1 Location of assemblages 
93As many animal bones cannot be reliably, confidently or consistently identified to species (Pitt and Stewart in 94press), genus level data was used. 'Species' is used in this study as a general term meaning 'type', and includes 95multiple genera where applicable. Assemblages containing only one of the selected species were excluded for 96most analyses because they offer no insights into species relationships. This resulted in a dataset containing 97824 archaeological assemblages. Analysis of recovery method included all assemblages which provided 98information on bone condition $(n=340)$ and whether sieving had taken place $(n=454)$.

99

1004000 BCE bioclim layers (Hijmans et al. 2005) and comparable 4050 BCE Mauri et al (2015) layers (Pitt 2017) 101were used to downscale 2150 BCE layers (Mauri et al. 2015), for period 1, and 'Iron Age' and 'Roman' (Büntgen 1022011) layers for periods 2 and 3 respectively from modern bioclim (Hijmans et al. 2005) layers, assuming no 103change in the spatial distribution of weather patterns. This increased resolution to 2.5 arc-minutes, or approx. $1045 \mathrm{~km}$ at the equator. A 90m digital elevation model (CGIAR Consortium for Spatial Information 2008) provided 105altitude information. These variables were extracted at assemblage locations using ArcGIS (v.10.2.2).

106

107The community modelling method uses a Bayesian Belief Network (BBN) in the form of a Microsoft 8 Excel 108spreadsheet, developed by Stafford et al. (2015). This method has only previously been applied to ecological 109research but can be adapted to inform archaeological interpretation. The principal difference is that ecological 110studies use prediction of change to model a future outcome, while an archaeological study will use the known 111outcome to model a prediction of change, thus enabling identification or exclusion of the factors which have most 112likely shaped the archaeological record. Bayesian statistics use 'prior beliefs', which, in an ecological BBN, 113represent the belief that a given species may increase or decrease in the future, based on expert available $114 \mathrm{knowledge}$. For example, there is a belief that Species A will increase if climate change causes temperatures to 115rise, based on expert knowledge. The ecologist wants to predict how that will affect increase or decrease of 116interacting species, given their relationships with one another. The changing factor is known (an increase in 117Species A). The aim is to predict the outcome, i.e. does the model predict that an increase in Species A will lead 118 to an increase or decrease in Species $B$ and $C$ ?

119

120When used in archaeological studies, the prior beliefs predict increase or decrease in frequency of species 121 based on known changes in the past. Information present in the dataset provides parameters which are used to 122predict how a combination of multiple variables should affect species frequency. Comparison with the known 123record, specifically increases or decreases in species, explains whether the factors modelled are resulting in the 124observed changes over time. If the models fail to predict the known outcome, then other factors must explain the 125differences. For example, Species $A$ is known to have increased in frequency in the Roman period, but it is not 126known how this may this have affected increase or decrease of interacting species, given their relationships with 127one another. The archaeologist knows which other species increased or decreased over the same time period 128and needs to establish whether these changes are connected. If Species B is known from the archaeological 
129record to have increased and the model predicts that an increase in Species A will result in an increase in 130 Species $B$, then it is possible that the increase in both species may be more than coincidence. If the model 131predicts that an increase in Species A will result in a decrease in Species $B$, then it is unlikely that the increase in 132Species B was related to the increase in Species A and other variable changes can then be modelled to find a 133better match for the outcome (increase in species $B$ ).

134

135There are three stages in a BBN:

136 1. An interaction matrix explaining the strength of any interaction between two variables

137 2. An interaction matrix containing whether an interaction is present

138 3. Prior beliefs (see above)

139

140

141Stage 1: We calculated a value between 0-1 representing the strength of the relationship between two variables. 142This reflects the probability of increase or decrease of pairs of variables, whereby a value of 0.5 represents no 143relationship, a value of 1 indicates that variable $A$ would increase with variable $B$, and a value of 0 would indicate 144that variable $A$ would decrease with variable $B$. This was established for each pair of variables by calculating how 145the relationships compare to what would be expected by chance:

146

$147 x=\frac{\sum \text { variable A e.g. chicken bones } \times \sum \text { variable Be.g.duck bones }}{\sum \text { total of all variables }(e . g . \text { total bones })}$

148for variables based on frequency (e.g. species or site type); or

$149 \times()=\frac{\sum \text { variable } A(e \cdot g \cdot \text { elevation })}{n()(\text { number of assemblages })}$

150for variables based on averages (e.g. climate or elevation), where $x$ represents the expected value;

151

152and then establishing how far this interaction differs from a value of 0.5 , representing no relationship:

$153 \begin{gathered}\sum_{y=\sigma i} \text { variable } A \\ \text { ) }\end{gathered}$

154where $y$ represents standard deviation

$155 z=($ variable $A()-x) \div y$

156where $z$ represents the difference between the observed and expected totals

$157 B B N$ value $=\left(\frac{z}{s d}\right)+0.5$ (value of no relationship) ,

158where $s d$ represents the number of standard deviations required to scale the data to a value between 0 and 1 , 159 with a minimum value of $s d=3$.

160 
161Stage 2: If an interaction (positive or negative) was present, this was input into the second stage of the BBN. 162Based on the formula above, relationships of 0.55 or above and 0.45 or below were interpreted as interactions. 163 As 0.5 represents no change, the range between 0.45 and 0.55 is unlikely to represent a meaningful 164relationship.

165

166Stage 3: We then adjusted the prior beliefs.. The model uses Bayesian inference to assess how changes, based 167on observations from the archaeological record (e.g. an increase in chicken), would affect the other variables in 168the study, based on their interactions with one another. Where a known increase or decrease occurred, albeit 169 limited by caveats associated with archaeological excavation (Pitt and Stewart in press), the prior belief was 170adjusted to 1 or 0 respectively.

171

172Species were selected based on association with chicken within specific spheres of interest (Table 1). The 173chicken is found in the domestic sphere, along with the other primary domestic animals, dog, horse, pig, 174sheep/goat, and the domestic birds, duck, goose and pigeon. Cattle were not selected for this analysis, as it has 175been noted that comparison of cattle with other primary mammals and with birds is problematic, due to disposal 176practices, recovery and preservation issues (Maltby 1997; Maltby 2010). It should be noted that duck, goose or 177pigeons found on archaeological sites are not necessarily domestic but may have been merely tamed (Albarella 1782005), or may represent other duck species (Parker 1988). Many of the selected domestic species are also 179edible, as are partridge and quail, although partridge and quail are additionally of interest for their use as fighting 180birds (Jennison 1937; Gal 2008).

\begin{tabular}{ll}
\hline & Genera \\
\hline Chicken & Gallus \\
Duck & Canis \\
Fox & Anas, Aythya \\
Goose & Vulpes \\
Horse & Anser, Branta \\
Marten & Equus \\
Mouse & Martes \\
Partridge & Apodemus, Mus, Micromys \\
Pig & Alectoris, Perdix \\
Pigeon & Sus \\
Quail & Columba \\
Rat & Coturnix \\
Sheep/goat & Rattus \\
Sparrow & Capra, Ovis \\
Weasel/stoat & Passer \\
\hline 181Table 1 Selected species.
\end{tabular}

181 Table 1 Selected species.

182

1833. Results and discussion 
1843.1 Analysis of changes in the faunal record

185The known outcome from the archaeological data forms the prior beliefs and allows interpretation of the 186Bayesian belief models. This study is concerned with understanding how known increases in chicken affected 187other species with which it is associated, and whether changes in the frequency of those species may have 188 contributed to the increase in frequency of chicken found on archaeological sites. The data were analysed to 189establish how species populations changed over time (Table 2).

\begin{tabular}{|c|c|c|c|c|c|c|c|c|}
\hline & \multicolumn{2}{|c|}{$\begin{array}{l}\text { Period } 1 \\
\text { (to } 800 \mathrm{BCE} \text { ) }\end{array}$} & \multicolumn{2}{|c|}{$\begin{array}{l}\text { Period } 2 \\
\text { (800 BCE - 0/42 CE) }\end{array}$} & \multicolumn{2}{|c|}{$\begin{array}{l}\text { Period } 3 \\
(1 / 43-500 \mathrm{CE})\end{array}$} & \multirow[b]{2}{*}{$\begin{array}{l}\text { Total } \\
\text { NISP }\end{array}$} & \multirow[b]{2}{*}{ Total Sites } \\
\hline & NISP & No. of sites & NISP & No. of sites & NISP & $\begin{array}{l}\text { No. of } \\
\text { sites }\end{array}$ & & \\
\hline Chicken & 16 & 2 & 4157 & 221 & 90040 & 468 & 94213 & 691 \\
\hline Dog & 1087 & 23 & 21336 & 237 & 39903 & 356 & 62326 & 616 \\
\hline Duck & 106 & 8 & 360 & 74 & 3415 & 197 & 3881 & 279 \\
\hline Fox & 152 & 14 & 952 & 70 & 495 & 51 & 1599 & 135 \\
\hline Goose & 44 & 6 & 308 & 59 & 4697 & 169 & 5049 & 234 \\
\hline Horse & 542 & 17 & 42164 & 237 & 42881 & 398 & 85587 & 652 \\
\hline Marten & 263 & 6 & 72 & 9 & 16 & 12 & 351 & 27 \\
\hline Mouse & 0 & 0 & 215 & 16 & 906 & 44 & 1121 & 60 \\
\hline Partridge & 20 & 4 & 39 & 12 & 598 & 32 & 657 & 48 \\
\hline Pig & 7084 & 27 & 302716 & 275 & 216385 & 445 & 526185 & 747 \\
\hline Pigeon & 3 & 2 & 515 & 26 & 799 & 104 & 1317 & 132 \\
\hline Quail & 0 & 1 & 7 & 5 & 37 & 6 & 44 & 12 \\
\hline Rat & 23 & 2 & 84 & 2 & 264 & 24 & 371 & 28 \\
\hline Sheep/goat & 14524 & 27 & 341695 & 277 & 273019 & 446 & 629238 & 750 \\
\hline Sparrow & 0 & 0 & 50 & 7 & 69 & 12 & 119 & 19 \\
\hline Weasel/stoat & 6 & 3 & 46 & 18 & 209 & 29 & 261 & 50 \\
\hline Total & 23870 & 28 & 714716 & 292 & 673733 & 504 & 1412319 & 824 \\
\hline Database & 10588 & 647 & 100270 & 3242 & 116471 & 7520 & 2273308 & 11409 \\
\hline $\begin{array}{l}\text { Total (all } \\
\text { mammals } \\
\text { and birds) }\end{array}$ & 8 & & 2 & & 8 & & & \\
\hline
\end{tabular}

191Domestic animals dominate the evidence in all periods, with bones of pig and sheep/goat recovered in greatest 192frequency. Chicken is present in small numbers by period 2. By period 3 it is widespread with larger populations. 193The change in frequency of chicken is paralleled by other species, including duck, goose, mouse, partridge, 194quail, rat and weasel/stoat. Sparrow and pigeon also increase in frequency in period 3, but are present in 195reasonable numbers in period 2. The increase in evidence of chicken in period 3 coincides with decreases in fox, 196marten, pig and sheep/goat. The primary edible mammals experience minor population decreases in period 3 , 197but horse and dog continue to increase. Marten decrease over both periods.

198

1993.2 Bayesian belief network analyses 
201A species relationship matrix was calculated using the formula in Section 2 (Table 3). In terms of the effect of the 202chicken on other species, the results show that assemblages containing chicken are more likely to contain dog, 203duck, goose, horse, partridge, pig, pigeon, and rat than expected by chance. They are less likely to contain fox 204and marten. In terms of species affecting the chicken, chicken is more likely to occur with goose, mouse, pigeon, 205quail, sheep/goat and sparrow, and less likely to occur with dog, duck, fox, horse, pig, and weasel/stoat. The 206domestic mammals are largely unaffected by other species and, where they have a relationship with other 207animals, then it is another domesticate. The domestic birds are affected by a mix of wild and domestic species, 208both positively and negatively.

\begin{tabular}{|c|c|c|c|c|c|c|c|c|c|c|c|c|c|c|c|c|}
\hline & 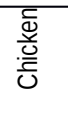 & סे & $\begin{array}{l}\text { Y } \\
\text { O } \\
\end{array}$ & 잔 & 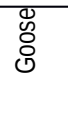 & $\begin{array}{l}\text { W } \\
\text { 호 } \\
\text { (2) }\end{array}$ & 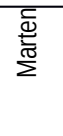 & 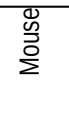 & 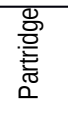 & $\frac{0}{2}$ & 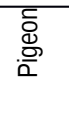 & $\begin{array}{l}\overline{\overline{\mathrm{U}}} \\
\mathrm{O}\end{array}$ & $\overline{\widetilde{\pi}}$ & 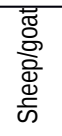 & 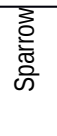 & 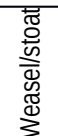 \\
\hline Chicken & 0.50 & 0.56 & 0.60 & 0.39 & 0.71 & 0.58 & 0.27 & 0.47 & 0.56 & 0.57 & 0.64 & 0.49 & 0.58 & 0.54 & 0.53 & 0.53 \\
\hline Dog & 0.40 & 0.50 & 0.46 & 0.57 & 0.36 & 0.57 & 0.61 & 0.48 & 0.40 & 0.55 & 0.39 & 0.44 & 0.54 & 0.55 & 0.46 & 0.51 \\
\hline Fox & 0.35 & 0.48 & 0.38 & 0.50 & 0.41 & 0.53 & 0.66 & 0.25 & 0.41 & 0.52 & 0.41 & 0.34 & 0.35 & 0.50 & 0.41 & 0.31 \\
\hline Goose & 0.64 & 0.46 & 0.59 & 0.42 & 0.50 & 0.48 & 0.33 & 0.42 & 0.50 & 0.53 & 0.47 & 0.55 & 0.34 & 0.46 & 0.37 & 0.25 \\
\hline Horse & 0.42 & 0.59 & 0.48 & 0.58 & 0.36 & 0.50 & 0.63 & 0.48 & 0.38 & 0.57 & 0.34 & 0.42 & 0.30 & 0.56 & 0.48 & 0.31 \\
\hline Marten & 0.50 & 0.49 & 0.54 & 0.52 & 0.55 & 0.49 & 0.50 & 0.62 & 0.63 & 0.51 & 0.53 & 0.46 & 0.46 & 0.49 & 0.44 & 0.45 \\
\hline Pigeon & 0.66 & 0.54 & 0.61 & 0.48 & 0.63 & 0.44 & 0.43 & 0.57 & 0.68 & 0.48 & 0.50 & 0.44 & 0.41 & 0.50 & 0.58 & 0.39 \\
\hline Quail & 0.55 & 0.48 & 0.53 & 0.50 & 0.55 & 0.49 & 0.51 & 0.43 & 0.56 & 0.49 & 0.53 & 0.50 & 0.58 & 0.51 & 0.45 & 0.74 \\
\hline Rat & 0.51 & 0.49 & 0.55 & 0.50 & 0.55 & 0.49 & 0.51 & 0.69 & 0.64 & 0.50 & 0.55 & 0.50 & 0.50 & 0.50 & 0.45 & 0.75 \\
\hline Sheep/goat & 0.97 & 0.92 & 0.88 & 0.92 & 0.73 & 0.91 & 0.61 & 0.90 & 0.91 & 0.91 & 0.90 & 0.87 & 0.94 & 0.50 & 0.90 & 0.89 \\
\hline Sparrow & 0.59 & 0.51 & 0.49 & 0.56 & 0.52 & 0.50 & 0.49 & 0.45 & 0.46 & 0.47 & 0.47 & 0.69 & 0.51 & 0.52 & 0.50 & 0.46 \\
\hline Weasel/stoat & 0.43 & 0.47 & 0.42 & 0.46 & 0.43 & 0.51 & 0.41 & 0.40 & 0.39 & 0.51 & 0.40 & 0.37 & 0.57 & 0.50 & 0.53 & 0.50 \\
\hline
\end{tabular}

209Table 3 Matrix of inter-species relationships, whereby the species in the row affects the species in the column. Light grey 210represents a positive relationship, dark grey represents a negative relationship and white indicates no relationship.

211

212For the first model (Figure 1), using biotic variables only, the intention is to determine the effect of the chicken on 213other species. The species interactions (Table 3) were used for stages one and two of the BBN, and the prior for 214chicken in the third stage was altered from 0.5 (no change) to 1 (increase), based on the known increase in 215chicken in both periods evident in the archaeological record (Table 2). 


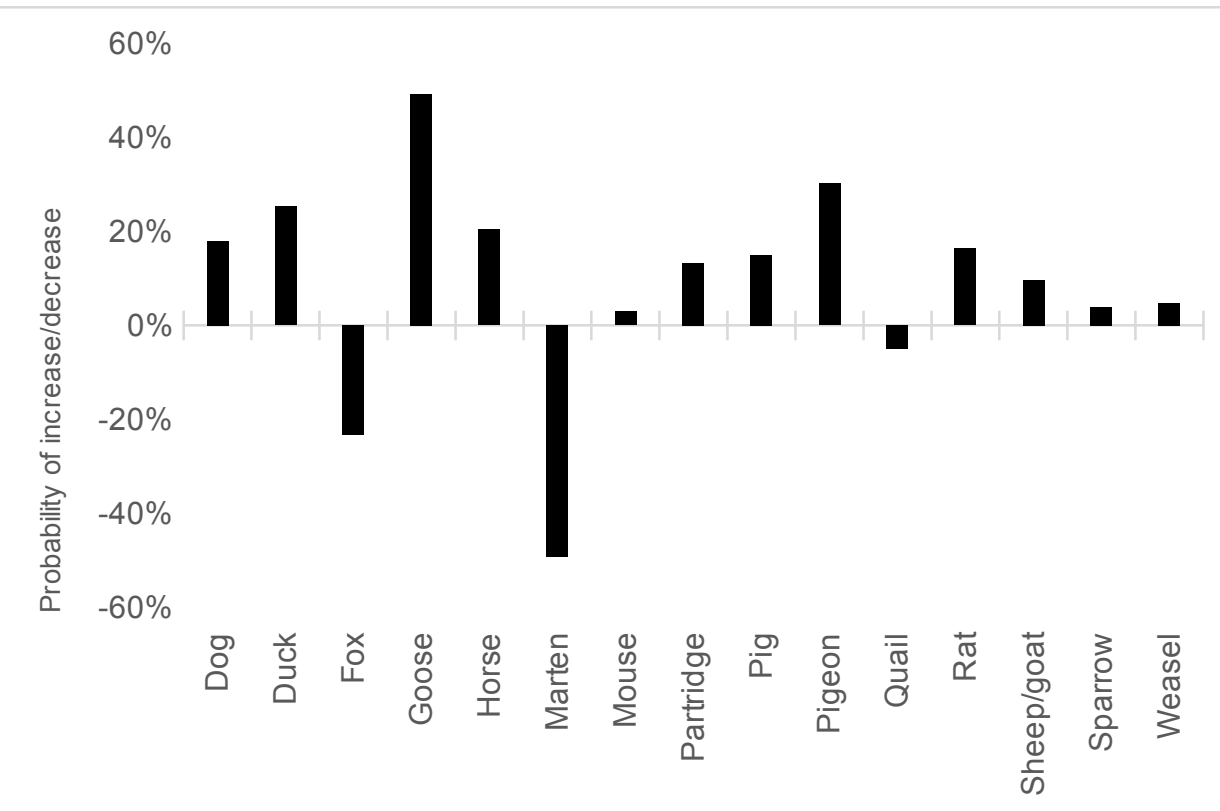

Affect on species predicted by increasing frequency of chickens

216

217Figure 1. BBN model predictions for change in species frequency when chicken frequency increases.

218The results show that when the relationships of the other species with each other are considered, an increase in 219chicken is predicted to have a negative impact on fox, marten and quail. Its increase should coincide with 220increases in all other species. Fox and quail increase in period 2 despite increase in chicken, suggesting that 221chicken is not likely to be an over-riding factor. Decrease in marten coincides with increase in chicken, and so 222chicken is not excluded as a factor. However, only limited increase in chicken in period 2 makes it difficult to 223draw firm conclusions. In period 3, a relatively large increase in chicken corresponds with the patterns seen for 224all species except quail, pig and sheep/goat. Increase in chicken, therefore, is unlikely to have affected quail, pig 225and sheep/goat.

226

227The prior beliefs of the species 'affecting' the chicken were altered in turn in the third stage of the model (Figure 2282). Periods 2 and 3 were modelled separately due to some of the interacting species increasing in one period 229(value=1), but decreasing (value=0) in another (Table 2). 


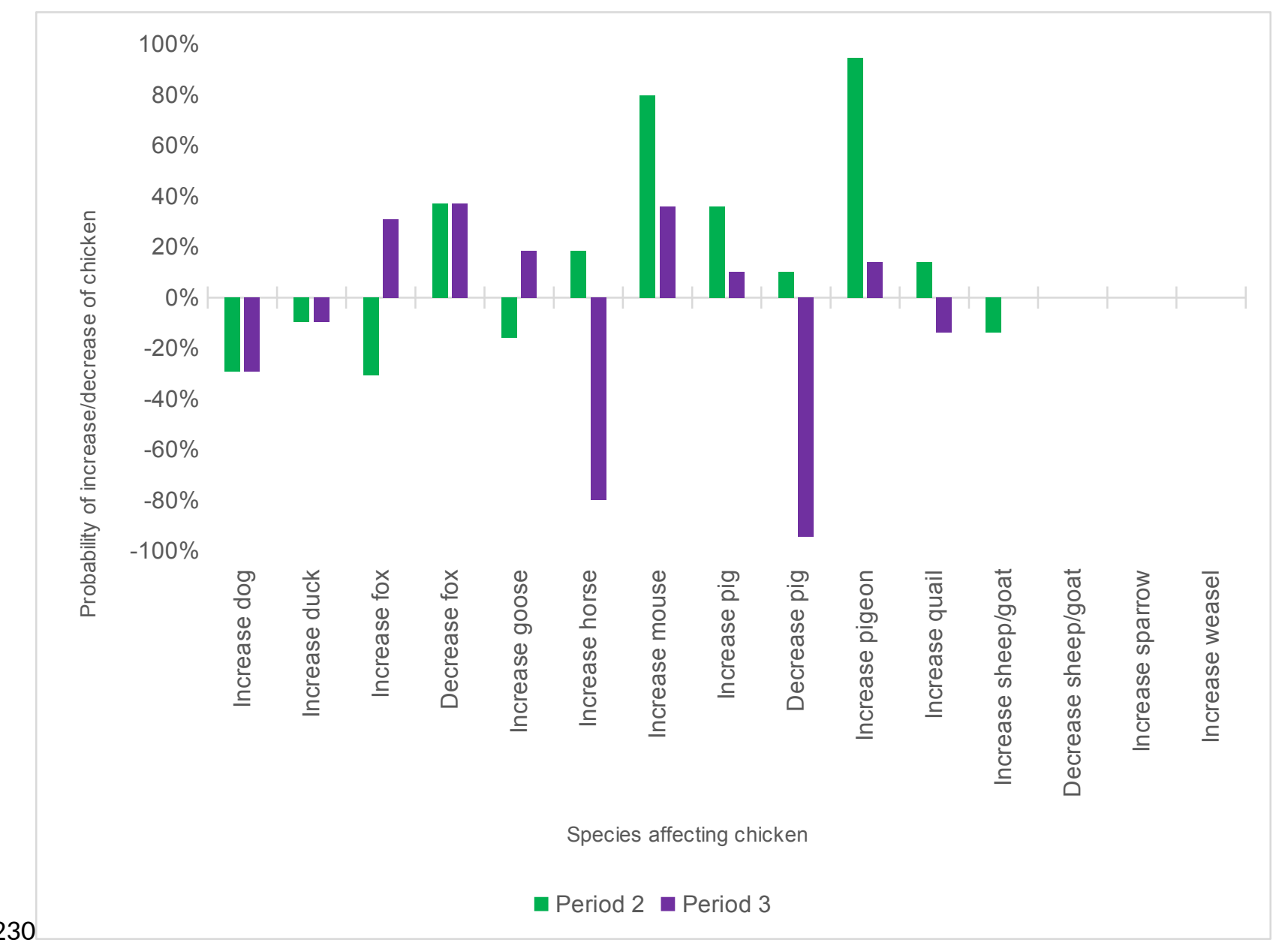

231Figure 2. BBN model prediction for changes in chicken frequency caused by changes in frequency of species affecting 232chicken.

233

234Limited increase in chicken in period 2 could be explained by dog, duck, fox, horse and weasel/stoat inhibiting 235increase, or goose, mouse, pig, pigeon, quail, sheep/goat and sparrow aiding it. Given the relatively large 236increase of chicken in period 3, predictions of dog, duck, pig, sheep/goat and weasel/stoat causing decrease in 237chicken suggests that these species are not influencing factors. Conversely, decrease in fox and increase in 238goose, mouse, pigeon, quail, and sparrow in period 3 parallel the archaeological record and cannot be excluded.

\subsection{2: Biotic and abiotic interactions}

241Abiotic variables provide information regarding factors outside of the ecological community which could have 242caused the changes observed in the archaeological record. We included site type, climate and elevation 243variables. Religious sites are sites with a primary function of ritual, religious, or funerary use, including ritual 244feasting, temples, sanctuaries, cult sites, and cemeteries. Rural sites are permanent settlements associated with 245rural activity or comprising a series of dwellings in insufficient number to be defined as urban. Urban sites are 246permanent settlements with a high density of dwellings and other buildings. If these factors do not better explain 
247the observed changes, then they are unlikely to be major driving factors. The relationships between the abiotic 248variables and both the chicken and the species affected by chicken (Table 4), were calculated as per the method 249in Section 2.

\begin{tabular}{|c|c|c|c|c|c|c|c|c|c|c|c|}
\hline & $\begin{array}{l}\frac{\bar{d}}{\mathrm{~d}} \\
\frac{\mathrm{d}}{\overline{\mathrm{U}}}\end{array}$ & ס্ঠ & $\begin{array}{l}\text { I } \\
\text { Ò }\end{array}$ & 希 & $\begin{array}{l}\text { 心 } \\
\text { ర్ర } \\
\text { ర) }\end{array}$ & 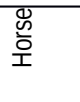 & 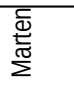 & 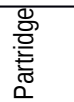 & 몸 & 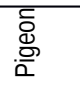 & वृ \\
\hline Religious & 0.65 & 0.45 & 0.5 & 0.43 & 0.5 & 0.5 & 0.5 & 0.5 & 0.5 & 0.58 & 0.61 \\
\hline Rural & 0.5 & 0.56 & 0.5 & 0.63 & 0.5 & 0.5 & 0.65 & 0.5 & 0.5 & 0.45 & 0.86 \\
\hline Urban & 0.39 & 0.5 & 0.55 & 0.44 & 0.5 & 0.5 & 0.39 & 0.55 & 0.5 & 0.5 & 0.03 \\
\hline Elevation & 0.46 & 0.40 & 0.27 & 0.47 & 0.29 & 0.41 & 0.83 & 0.91 & 0.43 & 0.58 & 0.61 \\
\hline Temperature & 0.5 & 0.43 & 0.38 & 0.5 & 0.4 & 0.42 & 0.5 & 0.94 & 0.5 & 0.5 & 0.62 \\
\hline Precipitation & 0.4 & 0.38 & 0.43 & 0.21 & 0.3 & 0.39 & 0.43 & 0.94 & 0.43 & 0.76 & 0.68 \\
\hline
\end{tabular}

250 Table 4. Matrix of species relationships with climate and environment variables, whereby the variable in the row affects the 251 species in the column. Light grey represents a positive relationship, dark grey represents a negative relationship and white 252indicates no relationship.

253

254The abiotic variable relationships were added to stages one and two of the model. The inter-species 255relationships were retained. The prior beliefs of each of the abiotic variables were altered in the third stage of the 256model to reflect known changes (Figure 3), as observed in historical records (climate) or derived from the 257dataset (elevation at site locations and site type). Known changes in period 2, compared to period 1, include a 258decrease in religious sites; and increase in rural and urban sites. The average height of a site above sea level 259increases, as does annual rainfall. In period 3, urban sites increase at the expense of rural sites; sites are 260located at lower elevation, and annual rainfall decreases slightly, compared to period 2. 

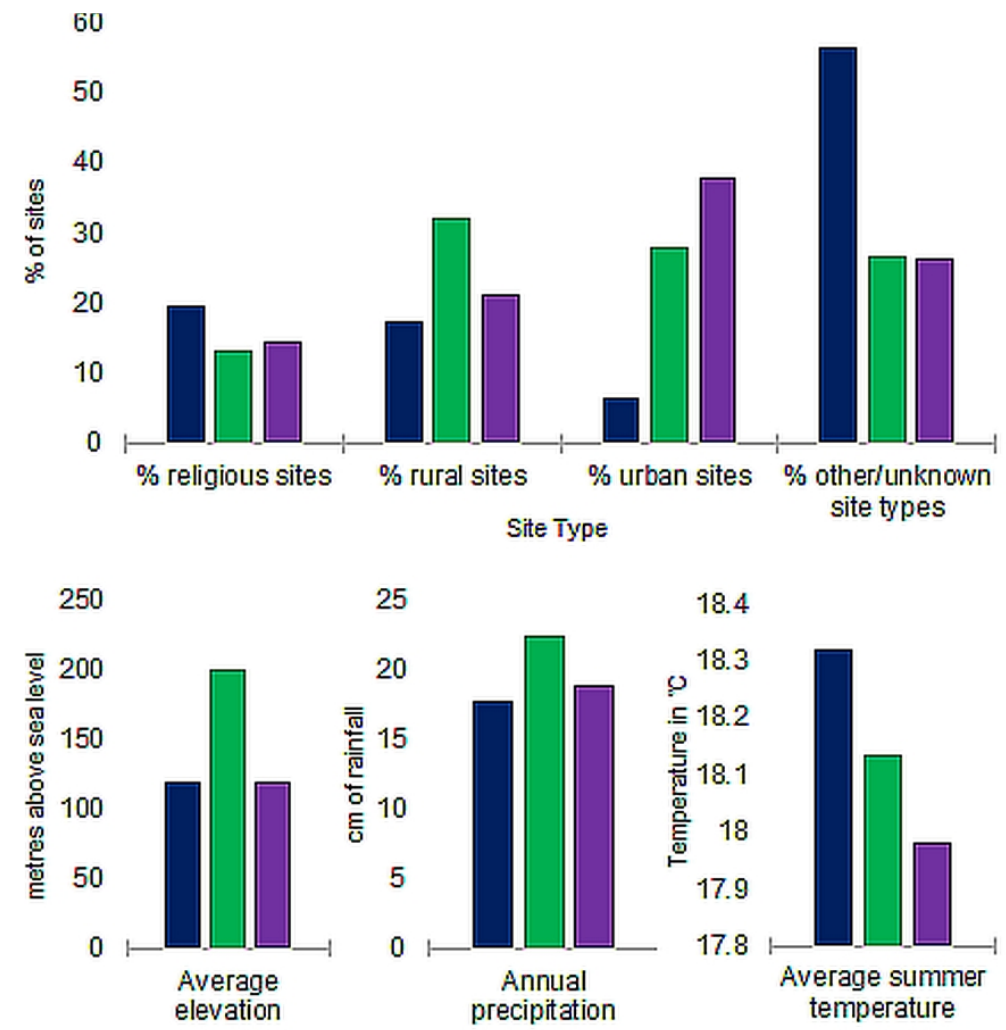

261匹Period 1 (to $800 \mathrm{BCE})$ घPeriod 2 (800 BCE - 0/42 CE) घPeriod 3 (1/43 - $500 \mathrm{CE}$ )

262Figure 3. Changes in abiotic variables between periods 1-3.

263The results (Figure 4) show that increase in religious sites, decrease in precipitation and a move to lower 264elevations may help to explain the rise in chicken numbers. The increase in urban spread, which is predicted to 265negatively affect the chicken is due, in part, to high frequency of chicken bones found at religious sites (Table 5). 266Greater human occupation provides convincing reasons for the decline of the marten in both periods 2 and 3 , 267due to negative responses to increased rural settlements (the reverse of the chart in period 2) and increase in 268urban settlements in period 3, which also tend to occupy lower elevations. The abiotic variables do not explain 269the patterns seen for pigeon, partridge, rat or fox, suggesting other factors are affecting these species. 


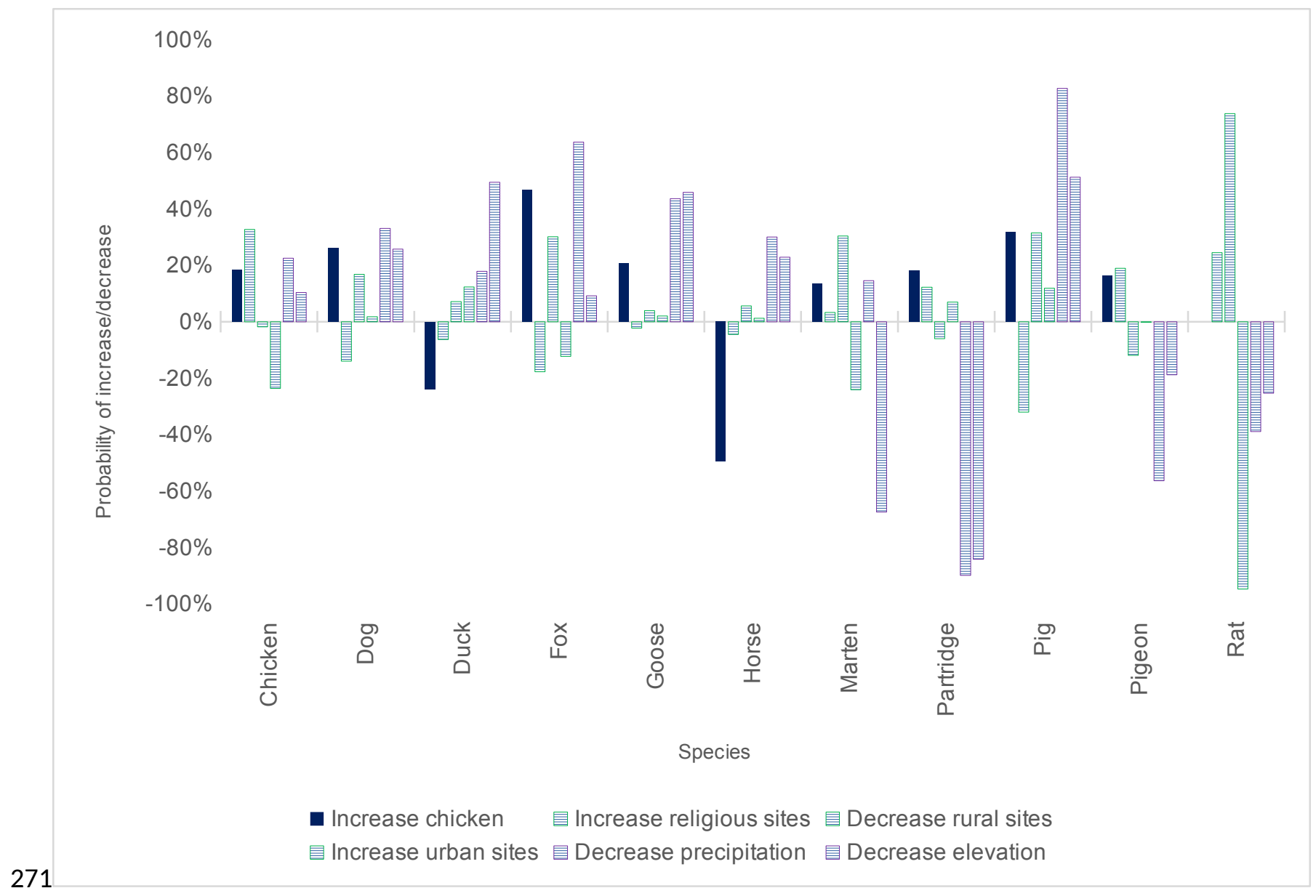

272Figure 4. BBN model prediction for response of chicken and species affected by chicken to climate and environmental 273 variables.

\begin{tabular}{ll}
\hline Species & $\begin{array}{l}\text { Frequency on religious sites } \\
(\mathrm{n}=131)\end{array}$ \\
\hline Pig & 119 \\
Chicken & 114 \\
Sheep/goat & 108 \\
Dog & 74 \\
Horse & 71 \\
Goose & 39 \\
Duck & 34 \\
Pigeon & 25 \\
Fox & 18 \\
Mouse & 16 \\
Partridge & 9 \\
Weasel/stoat & 6 \\
Rat & 5 \\
Sparrow & 4 \\
Marten & 2 \\
Quail & 2 \\
\hline
\end{tabular}

274Table 5. Species occurrence on religious sites. 


\subsubsection{Recovery methods}

2770ne of the main benefits of this kind of model is that it is not limited to purely environmental variables. This 278allows testing of a further theory- that the frequency of small animals is affected by excavation recovery 279methods. Larger bones are easier to detect during hand excavation, and smaller ones more likely to be missed 280unless contexts are sieved (Payne 1972; Sapir-Hen et al. 2017). Other factors influence whether sieving is part 281of the excavation methodology, and these were included in the models. Type of site was included because 282religious sites, particularly burials and cremations, are more likely to be sieved. This was confirmed by the 283relationship calculation (Table 6 and 7), after the method presented in Section 2. The type of excavation, whether 284commercial, rescue or research can influence the type of site excavated and whether sieving is performed. Bone 285 condition also affects whether more bones are recovered by sieving, and sieving was calculated to procure 286greater numbers of bones in poor condition.

\begin{tabular}{|c|c|c|c|c|c|c|c|c|c|c|c|c|c|c|c|c|}
\hline & $\begin{array}{l}\frac{\bar{d}}{D} \\
\frac{\bar{d}}{\bar{U}} \\
\end{array}$ & $\overline{8}$ & 竞 & 希 & 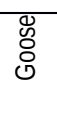 & 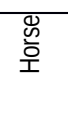 & 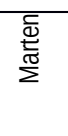 & 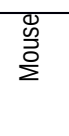 & 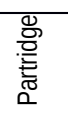 & 흠 & 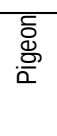 & $\begin{array}{l}\overline{\bar{\sigma}} \\
\overline{0}\end{array}$ & $\overline{\widetilde{\pi}}$ & $\begin{array}{l}\overline{\widetilde{\pi}} \\
\stackrel{0}{0} \\
\stackrel{0}{0} \\
\frac{0}{\omega}\end{array}$ & 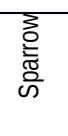 & 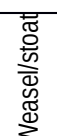 \\
\hline Hand excavated & 0.33 & 0.5 & 0.5 & 0.3 & 0.5 & 0.5 & 0.5 & 0.01 & 0.52 & 0.54 & 0 & 0.39 & 0.29 & 0.31 & 0.51 & 0.43 \\
\hline Sieved & 0.67 & 0.5 & 0.5 & 0.7 & 0.5 & 0.5 & 0.5 & 0.99 & 0.48 & 0.46 & 1 & 0.61 & 0.71 & 0.69 & 0.49 & 0.57 \\
\hline Good condition & 0.34 & 0.5 & 0.5 & 0.4 & 0.5 & 0.5 & 0.36 & 0.32 & 0.54 & 0.51 & 0.02 & 0.55 & 0.42 & 0.51 & 0.52 & 0.55 \\
\hline Poor condition & 0.68 & 0.5 & 0.5 & 0.43 & 0.56 & 0.5 & 0.64 & 0.69 & 0.46 & 0.5 & 0.58 & 0.47 & 0.43 & 0.48 & 0.5 & 0.46 \\
\hline Commercial & 0.45 & 0.88 & 1 & 0.58 & 0.69 & 0.51 & 0.44 & 0.48 & 0.45 & 0.47 & 0.44 & 0.42 & 0.71 & 0.52 & 0.48 & 0.46 \\
\hline Rescue & 0.67 & 0.43 & 0 & 0.49 & 0.5 & 0.44 & 0.79 & 0.3 & 0.27 & 0.36 & 0.32 & 0.3 & 0.18 & 0.64 & 0.8 & 0.27 \\
\hline Research & 0.38 & 0.19 & 0 & 0.43 & 0.31 & 0.55 & 0.27 & 0.72 & 0.78 & 0.67 & 0.74 & 0.78 & 0.61 & 0.34 & 0.23 & 0.77 \\
\hline Religious & 0.7 & 0.43 & 0.5 & 0.4 & 0.5 & 0.5 & 0.5 & 0.5 & 0.45 & 0.47 & 0.58 & 0.44 & 0.62 & 0.49 & 0.48 & 0.45 \\
\hline Rural & 0.44 & 0.56 & 0.5 & 0.61 & 0.44 & 0.5 & 0.69 & 0.5 & 0.47 & 0.49 & 0.39 & 0.46 & 0.8 & 0.52 & 0.7 & 0.7 \\
\hline Urban & 0.38 & 0.5 & 0.57 & 0.43 & 0.5 & 0.5 & 0.37 & 0.28 & 0.58 & 0.55 & 0.39 & 0.56 & 0.03 & 0.48 & 0.34 & 0.34 \\
\hline
\end{tabular}

287Table 6. Matrix of species and recovery method variables relationships, whereby the variable in the row affects the species in 288the column. Light grey represents a positive relationship, dark grey represents a negative relationship and white indicates no 289relationship.

290

\begin{tabular}{|c|c|c|c|c|c|c|}
\hline & 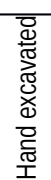 & $\begin{array}{l}\bar{d} \\
\stackrel{d}{\omega} \\
\bar{\omega}\end{array}$ & 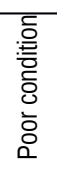 & 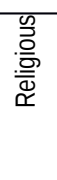 & $\begin{array}{l}\overline{\widetilde{\sigma}} \\
\overline{\underline{\alpha}}\end{array}$ & $\begin{array}{l}\text { 듀 } \\
\text { 总 }\end{array}$ \\
\hline Hand excavated & 0.5 & 0.5 & 0.5 & 0.38 & 0.5 & 0.5 \\
\hline Sieved & 0.5 & 0.5 & 0.5 & 0.62 & 0.5 & 0.5 \\
\hline Good condition & 0.5 & 0.5 & 0.5 & 0.5 & 0.5 & 0.5 \\
\hline Poor condition & 0.5 & 0.5 & 0.5 & 0.5 & 0.5 & 0.5 \\
\hline Commercial & 0.5 & 0.5 & 0.5 & 0.5 & 0.5 & 0.5 \\
\hline Rescue & 0.5 & 0.5 & 0.5 & 0.5 & 0.5 & 0.5 \\
\hline
\end{tabular}




\begin{tabular}{|c|c|c|c|c|c|c|}
\hline Research & $\begin{array}{l}0.7 \\
6\end{array}$ & 0 & 0.5 & 0.5 & 0.5 & 0.5 \\
\hline Religious & $\begin{array}{l}0.4 \\
3\end{array}$ & 0.73 & 0.5 & 0.5 & 0.5 & 0.5 \\
\hline Rural & 0.5 & 0.44 & 0.5 & 0.5 & 0.5 & 0.5 \\
\hline Urban & $\begin{array}{l}0.5 \\
5 \\
\end{array}$ & 0.33 & 0.5 & 0.5 & 0.5 & 0.5 \\
\hline
\end{tabular}

291Table 7. Matrix of recovery method variables relationships, whereby the variable in the row affects the variable in the column. 292Light grey represents a positive relationship, dark grey represents a negative relationship and white indicates no relationship.

294These relationships were used in stages one and two of the BBN to assess the predicted increase in NISP if 295 more sieving is done (value $=1$ in stage three) (Figure 5). Inter-species relationships were not included as they 296are not relevant to this analysis. The model predicts that nine of the species in this study are likely to benefit from 297more sieving, especially mouse and pigeon. Sieving would not decrease recovery of any of these species.

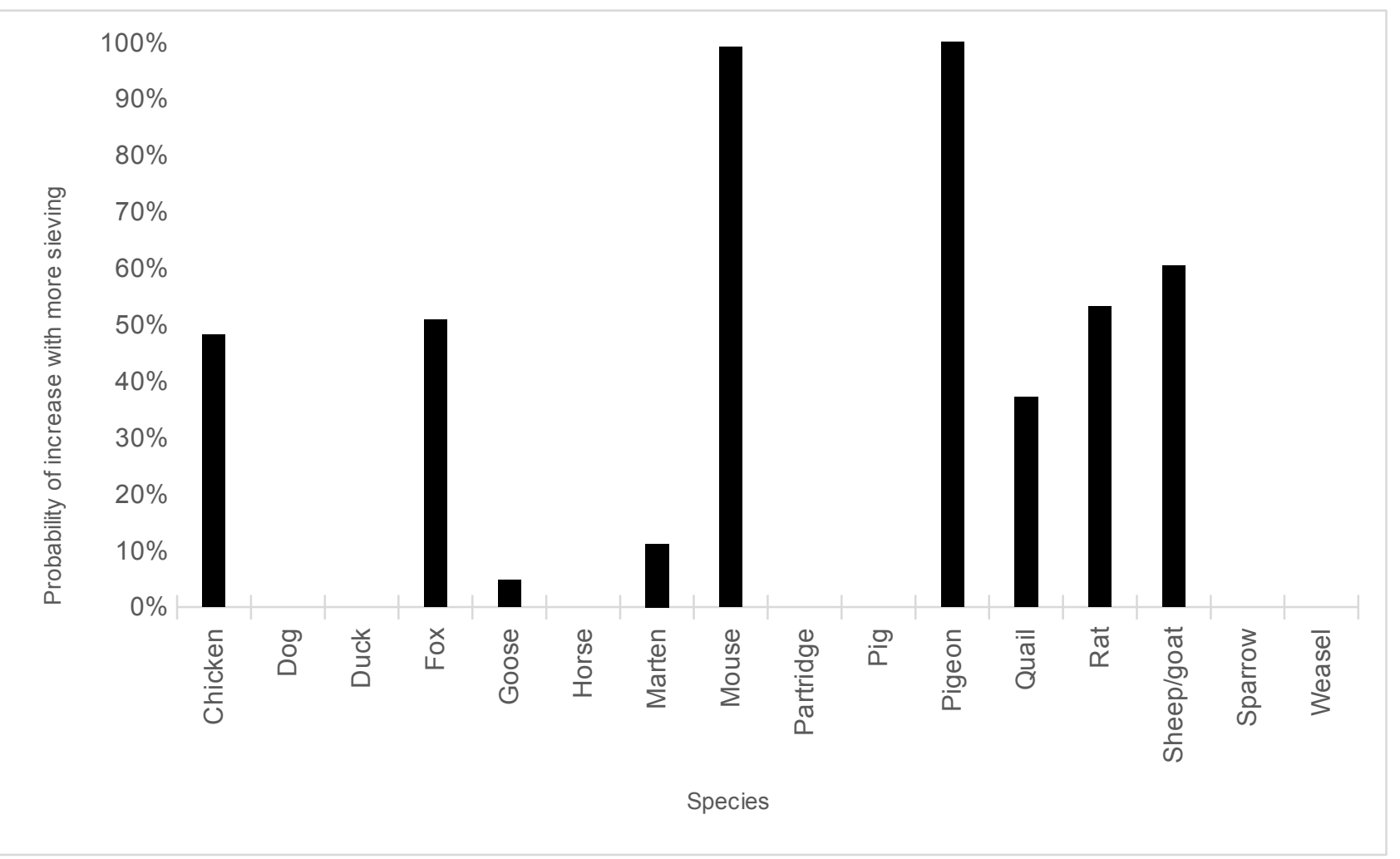

298

299Figure 5. BBN model prediction for recovery of animal bones with more sieving.

300

3014. Discussion: Analysis of presence on archaeological sites shows that increase in chicken occurs at the same 302time as changes in other species related to the chicken in various spheres of influence. Decreases in pig and 303sheep/goat and only minimal increase in horse in period 3 suggests that observed increase of other species is 304 not merely because of population size increases. The largest percentage change observed is the chicken in 305period 3. This large increase of chicken also coincides with increases in duck, goose, mouse, partridge, quail, rat 306and weasel/stoat and decreases in fox and marten. As a predator species, which is known to steal eggs, the 
307 fortune of the weasel/stoat contrasts with that of the fox and marten. This raises interesting observations for 308further analysis. Does the chicken affect the increase of weasel/stoat and cause fox and marten to decline? 309Perhaps the weasel/stoat is perceived differently by humans (after O'Connor 2013a)? Does the presence of 310other domestic species cause higher occurrence of chicken, and vice versa? Or does the increasing popularity of 311the chicken in period 3 cause proportional decreases in the primary domesticates? Does the method of feeding 312chickens enhance populations of commensal species such as mouse, rat, feral pigeon and sparrow? Are other 313 factors causing these changes instead?

314

315Calculating the relationships for the Bayesian belief network inter-species model identified that the ecosystem 316dynamics are different for domestic birds compared to domestic mammals, and, given the wide range of species 317that affect or are affected by chicken, the chicken belongs in a domestic sphere influenced by the other domestic 318birds. The models predicted that chicken neither influenced, nor was influenced by, the primary domestic 319mammals. Changing dietary patterns between periods 2 and 3 (King 1999) and particularly the varied diet 320enjoyed by the Romans (Rowan 2017), at least on some sites, might offer a good explanation for the increase in $321 \mathrm{birds}$, and slight decrease in domestic mammals. The models predict that goose and pigeon are most likely to 322increase chicken. This may be due to their position within the domestic sphere. Goose husbandry is well 323established by the Roman period, but duck domestication appears to be in its infancy, based on ancient literature 324(Albarella 2005). Positive association of duck with urban settlements and lower elevations may, therefore, be 325 explained by importation into towns (after Parker 1988). Association with religious sites, consistent with the 326 findings of King (2005), is predicted to be the abiotic variable most affecting chicken.

327

328Chickens are, however, known to be frequently found in towns (Maltby 1997). As common quail prefer open, 329agricultural habitats (BirdLife International 2016), it might be expected that they should not be found associated 330with chicken. Yet, an increase in quail is predicted to increase chicken populations. An increase in chicken, 331 however, is predicted to reduce numbers of quail. The known evidence suggests otherwise. They are both 332fighting, edible birds and quail could be imported to towns for these purposes. The same is true for partridge, the 333other fighting bird, which is predicted to increase with increased numbers of chicken. Environmental variables 334cannot explain what is seen in the faunal record. This suggests that the increase of the chicken is not to the 335detriment of the other potential fighting birds.

336

337Environmental variables, particularly the spread of urbanisation, deforestation, and construction of settlements at 338lower elevations explain the reduction of marten in the archaeological record better than the influence of chicken, 339although exacerbation by increase of chicken in period 3 is not discounted. The models show that the effect of 340the chicken on the other egg-thief, weasel/stoat is little more than expected by chance, and that the weasel/stoat 341does not, in fact, affect chicken. Of the predators, fox matches the pattern seen in the archaeological data, with 
342its increase perhaps inhibiting numbers of chicken initially and then experiencing population decline as chicken 343appears more frequently in the archaeological record.

344

345The other small birds, sparrow and pigeon, along with mouse and rat, are predicted to increase with increased 346 numbers of chicken, and thus the introduction of the chicken may have benefited these species. These species 347 are all small and recovery is likely to have been a major issue. Mouse, pigeon and rat were all shown to benefit 348from more sieving. This suggests that the frequency of small mammals and birds present was, in all likelihood, 349 higher, but that they were not recovered. With the exception, perhaps, of pigeon, they are all also species which 350 have less direct human interaction and so their presence on archaeological sites is opportunistic. Their remains 351 are more likely to be found where humans have chosen to deposit their refuse, rather than in the main centres of 352human activity (O'Connor 2013b) and so are likely to be underrepresented in the archaeological literature.

353

354There is another explanation, not accounted for in the models, which could apply to rat and to fox. These two 355 species are a problem for chicken keepers because foxes can decimate a flock, while rats can contaminate feed 356and water and cause disease in humans (Graham 2015). Both animals would thrive around chickens, and eat 357their eggs, were it not for humans, who will take measures to protect their flock from them. This offers a good 358 explanation for the predicted and observed results for fox, which increases in period 2 while chicken is present, 359 but only in low frequency and has been newly introduced. It decreases in period 3 when chicken increases 360dramatically and humans are likely to have developed better means of protecting them. This is consistent with a 361study of Anglo-Saxon fauna, which identified no direct correlation between chicken and fox (Poole 2015). Poole 362(2015) suggested that, in these instances, humans may have been reducing the fox population as a threat to 363human infant burials.

364

3655. Conclusions: The impact of the chicken on its environment and of the environment on the chicken was 366examined using a novel method to identify and exclude potential causes and effects. Analysis of the 367relationships and associations between species found in similar spheres of human activity, and their responses 368to external environmental factors, allows us to establish which of the many possible correlations are likely to 369 have contributed to, or been most affected by, the success of the chicken in Europe. The results show that 370chicken demonstrate most affinity with the other domestic birds. Where chicken is found, goose and pigeon are 371 more likely to be found, and, indirectly, duck via a positive mutual relationship between duck and goose. Its 372introduction and success did not affect the primary domestic mammals, nor the other fighting birds, quail and 373partridge, possibly due to their use as food also.

374

375The introduction of the chicken was shown to most affect fox, partridge and pigeon. Increase in chicken, directly 376or indirectly, provides the best explanation for the decrease of fox, having established that environmental 
377changes in period 3 should have led to increases in fox numbers. While the chicken may have contributed to the 378decline of marten, external environmental factors, particularly the spread of urbanisation, offer a better 379 explanation. Increase in chicken may have aided increases in mouse, quail and rat; although models suggest 380that recovery of these species, which are present in low numbers in the dataset, are affected by retrieval 381 methods and may be under-represented. Recovery models find that sieving would enhance recovery of nine of 382the sixteen species assessed (over $50 \%$ ), making it a worthy endeavour for small animal assemblages.

383

384The results are model predictions and must be interpreted as such. In this study, interpretation is restricted to 385 better understanding of the information present in the data. For future work, if two independent datasets were 386available, this would enable the user to establish the prior beliefs from one dataset, and use this information to 387 test hypotheses from another dataset. This would facilitate testing of site scale hypotheses as well as those at 388larger regional scales. Local or regional study of detailed recovery techniques may also provide interesting 389results. This study presents a method which can be easily applied to any archaeological dataset. It demonstrates 390how an inter-disciplinary approach, using novel ecological techniques, offers an efficient means of comparing 391various inter-related aspects of large quantities of data and can help to better interpret the archaeological record.

392

393Acknowledgments: This research was funded by Bournemouth University, in association with the AHRC (Grant 394No AH/L006979/1). We would like to thank the two anonymous reviewers who helped to improve this study. 


\section{References:}

396Albarella, U., 2005. Alternate fortunes? The role of domestic ducks and geese from Roman to 397Medieval times in Britain. In: Grupe, G. and Peters, J., eds. Feathers, grit and symbolism: Birds and 398humans in the ancient Old and New Worlds. Proceedings of the 5th Meeting of the ICAZ Bird Working 399Group in Munich [26.7.-28.7.2004]. Rahden: Verlag Marie Leidorf, 249-258.

400Araújo, M. B. and Rozenfeld, A., 2014. The geographic scaling of biotic interactions. Ecography, 37 401(5), 406-415.

402Baselga, A. and Araújo, M. B., 2009. Individualistic vs community modelling of species distributions 403under climate change. Ecography, 32 (1), 55-65.

404BirdLife International, 2016. Coturnix coturnix. The IUCN Red List of threatened species 2016: 405e.T22678944A85846515. [online]. Available from: http://dx.doi.org/10.2305/IUCN.UK.20164063.RLTS.T22678944A85846515.en [Accessed 1 February 2017].

407Boev, Z., 1993. Archeo-ornithology and the synanthropisation of birds: A case study for Bulgaria. 408Archaeofauna: Revista de la Asociación Española de Arqueozoología, 2, 145-153.

409Büntgen, U., Tegel, W., Nicolussi, K., McCormick, M., Frank, D., Trouet, V., Kaplan, J. O., Herzig, F., 410Heussner, K.-U., Wanner, H., Luterbacher, J. and Esper, J., 2011. 2500 years of European climate 411variability and human susceptibility. Science, 331, (6017), 578-582.

412CGIAR Consortium for Spatial Information, 2008. Resampled SRTM data to 250m resolution (based 413on SRTM 90m Digital Elevation Model) [online]. Available from: http://srtm.csi.cgiar.org/ [Accessed 16 414December 2015].

415Davis, S. J. M., 2012. The archaeology of animals. London: Routledge.

416Elevelt, S. C., 2012. Subsistence and social stratification in Northern lonic Calabria from the Middle 417Bronze Age until the Early Iron Age: the archaeozoological evidence. Thesis (Doctor of Philosophy). 418Groningen.

419Gal, E., 2008. Bone evidence of pathological lesions in domestic hen (Gallus domesticus Linnaeus, 4201758). Veterinarija ir Zootechnika, 41 (63), 42-48.

421Graham, C., 2015. The chicken keeper's problem solver. 100 common problems explored and 422explained. London: Hamlyn.

423

424Hijmans, R. J., Cameron, S. E., Parra, J. L., Jones, P. G. and Jarvis, A., 2005. Very high resolution 425interpolated climate surfaces for global land areas. International Journal of Climatology, 25 (15), 19654261978.

427Jennison, G., 1937. Animals for Show and Pleasure in Ancient Rome. Manchester University Press. 428King, A., 1999. Diet in the Roman world: a regional inter-site comparison of the animal bones. Journal 429of Roman Studies, 12, 168-202.

430King, A., 2005. Animal remains from temples in Roman Britain. Britannia, 36, 329-369

431Kissling, W. D., Dormann, C. F., Groeneveld, J., Hickler, T., Kühn, I., Mclnerny, G. J., Montoya, J. M., 432Römermann, C., Schiffers, K., Schurr, F. M., Singer, A., Svenning, J.-C., Zimmermann, N. E. and 433O'Hara, R. B., 2012. Towards novel approaches to modelling biotic interactions in multispecies 434assemblages at large spatial extents. Journal of Biogeography, 39 (12), 2163-2178.

435Lang, J. M. and Benbow, M. E., 2013. Species interactions and competition. Nature Education 436Knowledge, 4 (4), 8. 
437Maltby, M., 1997. Domestic fowl on Romano-British sites: inter-site comparisons of abundance. 438International Journal of Osteoarchaeology, 7 (4), 402-414.

439Maltby, M., 2010. Feeding a Roman town: environmental evidence from excavations in Winchester, 4401972-1985. Winchester: Winchester Museums.

441Mauri, A., Davis, B. A. S., Collins, P. M. and Kaplan, J. O., 2015. The climate of Europe during the 442Holocene: a gridded pollen-based reconstruction and its multi-proxy evaluation. Quaternary Science 443Reviews, 112, 109-127.

444McInerny, G. J. and Purves, D. W., 2011. Fine-scale environmental variation in species distribution 445modelling: regression dilution, latent variables and neighbourly advice. Methods in Ecology and 446Evolution, 2 (3), 248-257.

447Mooney, H. A. and Cleland, E. E., 2001. The evolutionary impact of invasive species. Proceedings of 448the National Academy of Sciences, 98 (10), 5446-5451.

449O'Connor, T. P., 1993. Birds and the scavenger niche. Archaeofauna: Revista de la Asociación 450Española de Arqueozoología, 2, 155-162.

451O'Connor, T., 2013a. Animals as neighbors: The past and present of commensal animals. East 452Lansing: Michigan State University Press.

453O'Connor, T., 2013b. The archaeology of animal bones. New York: The History Press.

454Parker, A. J., 1988. The birds of Roman Britain. Oxford Journal of Archaeology, 7 (2), 197-226.

455Parmentier, E. and Michel, L., 2013. Boundary lines in symbiosis forms. Symbiosis, 60 (1), 1-5.

456Payne, S., 1972. Partial recovery and sample bias: The results of some sieving experiments. In: 457Higgs, E. S., ed. Papers in Economic Prehistory. London: Cambridge University Press, 49-64.

458Pearson, R. G. and Dawson, T. P., 2003. Predicting the impacts of climate change on the distribution 459of species: are bioclimate envelope models useful? Global Ecology and Biogeography, 12 (5), 361460371.

461Pitt, J., 2017. The ecology of chickens: An examination of the introduction of the domestic chicken 462across Europe after the Bronze Age. Thesis (Doctor of Philosophy). Bournemouth University.

463Pitt, J., Gillingham, P. K., Maltby, M. and Stewart, J. R., 2016. New perspectives on the ecology of 464early domestic fowl: An interdisciplinary approach. Journal of Archaeological Science, 74, 1-10.

465Pitt, J. and Stewart, J. R., in press. Garbage in, garbage out? Issues and suggestions for small 466vertebrate zooarchaeological databases. Submitted to British Archaeological Reports.

467Pollock, L. J., Tingley, R., Morris, W. K., Golding, N., O'Hara, R. B., Parris, K. M., Vesk, P. A. and 468McCarthy, M. A., 2014. Understanding co-occurrence by modelling species simultaneously with a Joint 469Species Distribution Model (JSDM). Methods in Ecology and Evolution, 5 (5), 397-406.

470Poole, K., 2015. Foxes and badgers in Anglo-Saxon life and landscape. Archaeological Journal, 172 471(2), 389-422.

472Rowan, E., 2017. Sewers, archaeobotany, and diet at Pompeii and Herculaneum. In: Flohr, M. and 473Wilson, A., eds. The economy of Pompeii. Oxford: Oxford University Press, 111-134.

474Sapir-Hen, L., Sharon, I., Gilboa, A. and Dayan, T., 2017. Wet sieving a complex tell: Implications for 475retrieval protocols and studies of animal economy in historical periods. Journal of Archaeological 476Science, 82, 72-79. 
477Soberón, J. and Nakamura, M., 2009. Niches and distributional areas: Concepts, methods, and 478assumptions. Proceedings of the National Academy of Sciences, 106 (Supplement 2), 19644-19650.

479Spiers, E. K. A., Stafford, R., Ramirez, M., Vera Izurieta, D. F., Cornejo, M. and Chavarria, J., 2016. 480 Potential role of predators on carbon dynamics of marine ecosystems as assessed by a Bayesian 481belief network. Ecological Informatics, 36, 77-83.

482Stafford, R., Williams, R. L. and Herbert, R. J. H., 2015. Simple, policy friendly, ecological interaction 483models from uncertain data and expert opinion. Ocean \& Coastal Management, 118, Part A, 88-96.

484Stewart, J. R., 2009. The evolutionary consequence of the individualistic response to climate change. 485Journal of Evolutionary Biology, 22 (12), 2363-2375.

486Wilkinson, P., 2007. Archaeology : what it is, where it is, and how to do it. Oxford: Archaeopress.

487Wisz, M. S., Pottier, J., Kissling, W. D., Pellissier, L., Lenoir, J., Damgaard, C. F., Dormann, C. F., 488Forchhammer, M. C., Grytnes, J.-A., Guisan, A., Heikkinen, R. K., Høye, T. T., Kühn, I., Luoto, M., 489Maiorano, L., Nilsson, M.-C., Normand, S., Öckinger, E., Schmidt, N. M., Termansen, M., 490Timmermann, A., Wardle, D. A., Aastrup, P. and Svenning, J.-C., 2013. The role of biotic interactions in 491shaping distributions and realised assemblages of species: implications for species distribution 492modelling. Biological Reviews, 88 (1), 15-30.

493Zeiler, J. T. and de Vries, L. S., 2008. Archeozoölogisch onderzoek van de Romeinse stad Forum 494Hadriani (120-270 AD), gem. Leidschendam-Voorburg (LVB-FO 9888). Leeuwarden: ArchaeoBone.

495

496 